\title{
o que propóe o livro didático de Língua Portuguesa quando didatiza o gênero Artigo de Opinião? Investigações da obra "Português: contexto, interlocução e sentido"
}

\section{What does the Portuguese Language Textbook Propose When It Comes to the Genre Opinion Article? Investigations on the Portuguese Work: Context, Interlocution and Meaning}

Lenilton Damião da Silva Junior*

*Universidade de Pernambuco (UPE), Recife, Pernambuco / Brasil

leniltonjunior@globomail.com

https://orcid.org/0000-0001-8210-7650

Débora Amorim Gomes da Costa-Maciel**

**Universidade de Pernambuco (UPE), Recife, Pernambuco / Brasil deboracostamaciel@gmail.com

https://orcid.org/0000-0002-6408-1626

RESUMO: Neste trabalho, investiga-se a didatização do gênero artigo de opinião na coleção de livro didático Português: contexto, interlocução e sentido, com vistas a identificar as estratégias de ensino do gênero artigo de opinião e refletir sobre a proposta da obra para o seu processo de ensino-aprendizagem. Ressaltase a relevância do objeto de reflexão por ser o artigo de opinião um gênero textual/discursivo que, ao ser didatizado, pode favorecer o desenvolvimento da competência comunicativa para a tomada de decisões de interesse coletivo, e por ter a coleção recebido destaque na avaliação do Programa Nacional do Livro Didático (2015) como a única que tem a perspectiva discursiva de abordagem dos diversos eixos do ensino de língua portuguesa, além de atualização dos princípios teóricos que embasam o seu trabalho. Trata-se de uma pesquisa documental de base qualitativa e interpretativa, cujos dados foram tratados a partir de elementos da técnica de análise de conteúdo categorial definidas por Bardin (2009). Funda-se teoricamente no diálogo com os pressupostos teóricos do Interacionismo Sociodiscursivo, de Bronckart $(2006,1999)$ e de Schneuwly e Dolz (2004); no conceito de artigo de opinião, de Gonçalves e Higa (2012); e 
nas perspectivas de produção de textos no contexto escolar, de Antunes (2009, 2003). Evidencia-se que, embora existam estratégias que podem favorecer a elaboração do artigo de opinião, alguns problemas são identificados no material analisado, dentre eles a ausência de produção final articulada com o trabalho vivenciado no processo de reflexão sobre o gênero; fragmentação de textos que apoiam a discussão; bem como falta de articulação entre elementos que compõem o capítulo.

PALAVRAS-CHAVE: artigo de opinião; didatizações; livro didático.

\begin{abstract}
In this work, the didactization of the genre of opinion article is investigated in the textbook collection Português: contexto, interlocução e sentido, with the objective to identify the teaching strategies of the opinion article genre and to reflect on the proposal of the work for the teaching-learning process. The relevance of the object of reflection is emphasized because the article of opinion is a textual/discursive genre that, when didactized, can favor the development of communicative competence for collective interest decisionmaking, and for the collection having received prominence in the evaluation of the National Textbook Program (2015) as the only one that has the discursive perspective of approaching the various axes of Portuguese language teaching, as well as updating the theoretical principles that underpin its work. This is a qualitative and interpretive documentary research, whose data were treated using elements of the categorical content analysis technique defined by Bardin (2009). It is theoretically based on the dialogue with the theoretical assumptions of Sociodiscursive Interactionism, by Bronckart $(2006,1999)$ and Schneuwly and Dolz (2004), in the concept of an opinion article by Gonçalves and Higa (2012), and in the perspective of textual production in a school context, by Antunes $(2009,2003)$. It is evident that, although there are strategies that may favor the elaboration of the opinion article, some problems are identified in the analyzed material, among them the absence of final production articulated with the work experienced in the process of reflection on gender; fragmentation of texts that support the discussion; as well as lack of articulation between elements that make up the chapter.
\end{abstract}

KEYWORDS: opinion article; didactizations; textbook.

\title{
1 Introdução
}

Neste trabalho, investigamos a didatização do gênero artigo de opinião na coleção de livro didático Português: contexto, interlocução e sentido. De modo específico, identificamos as estratégias de ensino do gênero artigo de opinião e refletimos sobre a proposta da obra para o processo de ensinoaprendizagem do referido gênero.

Escolhemos investigar o gênero artigo de opinião por ser ele o mais utilizado no trabalho com a argumentação, segundo Dolz e Schneuwly (1996); e, também, por ele ser de fundamental importância para o 
desenvolvimento da capacidade reflexiva e crítica dos estudantes. A escolha da coleção Português: contexto, interlocução e sentido se deu em função de sua avaliação pelo Programa Nacional do Livro Didático - PNLD (BRASIL, 2015) ser a única coleção que tem como principal foco a perspectiva discursiva de abordagem dos diversos eixos do ensino de Língua Portuguesa (LP), além de oferecer, segundo o referido documento, a devida correção e atualização dos princípios teóricos que embasam o trabalho com estes eixos.

É sabido que, conforme explicita Bunzen (2001), ainda existem muitos mistérios relacionados ao uso e à escolha de livros didáticos. Bunzen (2005, p. 558) também afirma que o livro didático "se caracteriza muito mais por uma incompletude e por heterogeneidade de saberes, de crenças e de valores sobre a língua e seu ensino/aprendizagem do que num saber-fazer homogêneo e sem conflitos". Em contrapartida, Rangel (2003) nos diz que o livro didático de Língua Portuguesa "é parte indissociável de nossas concepções de leitura, literatura e, mais amplamente, de cultura letrada". Então, diante a presença do livro didático no contexto escolar, é necessário que investigações sejam direcionadas a esse suporte didático, uma vez que a sua presença em sala de aula representa, por vezes, o "instrumento principal que guia a ação docente” (ALBUQUERQUE; FERREIRA, 2019, p. 250).

Outro elemento a ser destacado em relação a pertinência de pesquisas em relação ao livro didático é que alguns livros de LP ainda apresentam proposta de ensino descontextualizada ou apresentam uma visão fragmentada de seus conteúdos, o que consiste em uma "polarização entre o estudo do texto e o estudo da frase, ou então o uso do texto como pretexto para ensinar gramática normativa" (GUIMARÃES, 2003, p. 153; ANTUNES, 2009, 2003; FARACO, 2008).

Contudo, não podemos esquecer que o docente deve refletir criticamente sobre o material utilizado no processo de ensino-aprendizagem, começando pela leitura crítica das avaliações de coleções de livros didáticos do PNLD. Em linhas gerais, o Guia de Livros Didáticos enfatiza que, nas coleções sobre as quais foram feitas resenhas, observou-se a preocupação com a ampliação e o aprofundamento da convivência do(a) aluno(a) com a diversidade e a complexidade da Língua Portuguesa em diferentes esferas de uso; com o desenvolvimento da proficiência do(a) aluno(a); com o desenvolvimento de uma visão sistemática quanto à construção progressiva de conhecimentos e, ainda, com o aumento da autonomia com relação aos seus estudos (BRASIL, 2014). Entretanto, os autores do Guia também 
alertam os educadores para que eles estejam atentos à materialidade dessas obras no momento de escolher qual delas será adotada pela escola a qual eles estão alocados.

É no contexto do livro didático, dentre outros suportes de texto, que o gênero artigo de opinião - assim como os outros gêneros discursivos - chega às escolas brasileiras. O referido gênero, agrupado por Dolz e Schneuwly (1996) na ordem do argumentar, é, de acordo com os Parâmetros Curriculares Nacionais de Língua Portuguesa para o Ensino Fundamental - PCN ${ }^{1}$ (BRASIL, 1998), de domínio fundamental para a efetiva participação social. Além disso, nas Diretrizes Curriculares Nacionais da Educação Básica (DCN), lançadas no ano de 2013, é enfatizado o ensino da argumentação, uma vez que se compreende que "[...] a democratização da sociedade exige, necessariamente, informação e conhecimento para que a pessoa possa situar-se no mundo, argumentar, reivindicar e ampliar novos direitos" (BRASIL, 2013, p. 528). Desse modo, a argumentação consiste em um importante exercício para compreensão do mundo e ação sobre ele. Ampliando, ainda mais, essa discussão sobre a relevância da argumentação para o desenvolvimento da consciência reflexivo-crítica dos alunos, na Base Nacional Comum Curricular - BNCC (BRASIL, 2017) defende-se a necessidade de os alunos - em todas as disciplinas curriculares - serem instigados a argumentar com base em fatos, dados e informações confiáveis para formular, negociar e defender ideias, pontos de vista e decisões comuns que respeitem e promovam os direitos humanos, a consciência socioambiental e o consumo responsável em âmbito local, regional e global, com posicionamento ético em relação ao cuidado de si mesmo, dos outros e do planeta.

Nessa direção, quando falamos sobre o gênero artigo de opinião, é imprescindível discorrer, também, sobre a argumentação, entendida como uma ação verbal na qual se utiliza a palavra oral ou escrita para defender uma tese a respeito de determinado fato. Assim, quem argumenta, vale-se de razões, fatos, virtudes e valores (éticos, estéticos e emocionais) que servem de alicerce para a tese defendida (RANGEL; GAGLIARDI; AMARAL, 2014).

\footnotetext{
${ }^{1}$ Os Parâmetros Curriculares Nacionais (PCN) é um documento datado, que auxiliou o trabalho pedagógico no Brasil a partir de 1997, época do governo de Fernando Henrique Cardoso, até o início do Governo Lula, quando o trabalho pedagógico passou a ser orientado pelas Diretrizes Curriculares Nacionais (2013).
} 
No que se refere à produção de texto, é necessário que os aspectos discursivos e notacionais do gênero artigo de opinião sejam efetivamente compreendidos e a produção dele seja experienciada pelos(as) alunos(as) do Ensino Médio (EM); mais do que isso, que também experienciada nas outras etapas da educação básica, pois é preciso sistematizar esse aprendizado, procurando dedicar um período de tempo específico para o conhecimento do gênero, identificação da tipologia textual predominante nele, sequência argumentativa, bem como a identificação dos elementos coesivos que conferem a progressão textual e a compreensão micro e macroestrutural do artigo de opinião.

Portanto, analisar como o trabalho com o artigo de opinião é conduzido ao longo de uma unidade didática é um exercício importante para a apreciação da adequabilidade do material didático à proposta de ensino de língua materna e, mais do que isso, é contribuir para a melhoria contínua da qualidade da educação básica brasileira. É nessa direção que o nosso artigo foi produzido, porque compreendemos que, ao tomar a proposta de didatização do artigo de opinião no livro didático como objeto de investigação, estamos colaborando também para entendermos as concepções da obra sobre o "ensino/aprendizagem e, ao mesmo tempo, revelando importantes aspectos para se compreender a educação no país” (ALBUQUERQUE; FERREIRA, 2019, p. 250).

$\mathrm{Na}$ primeira parte deste artigo discorremos sobre gêneros e aspectos tipológicos. Em seguida, conceituamos o gênero artigo de opinião e sua produção no contexto escolar, bem como a argumentação. $\mathrm{Na}$ segunda parte, detalharemos a metodologia adotada, seguida da análise do material. Após essas seções, apresentamos nossas considerações finais.

\section{Fundamentação teórica}

\subsection{Gêneros e aspectos tipológicos}

A discussão que traremos neste artigo está estruturada nas bases teóricas do Interacionismo Sociodiscursivo (ISD), corrente inspirada em estudos relacionados ao Interacionismo Social, que compreende textos como correspondentes empíricos de uma atividade de linguagem. Entendese atividade de linguagem como o aspecto fundamental de toda prática social ou individual (BRONCKART, 2006). 
Então, na perspectiva do ISD, o problema da linguagem é absolutamente central ou decisivo para as ciências humanas, uma vez que a linguagem é considerada não só como meio de expressão de processos estritamente psicológicos, mas também instrumento fundador e organizador deles, em suas dimensões especificamente humanas. Além disso, é pertinente a afirmação de que signos-ideias são produtos da interação social e são condicionados por ela, possuindo, assim, caráter dialógico.

Desse modo, a espécie humana operacionaliza seu agir comunicativo verbal, mobilizando signos organizados em textos. Estes, por sua vez, exigem a mobilização de recursos lexicais e sintáticos de uma determinada língua natural e modelos de organização textual disponíveis no âmbito dessa mesma língua, o que corrobora o entendimento de que os gêneros são correspondentes de atividades de linguagem (BRONCKART, 2006).

Nessa mesma direção argumentativa, Schneuwly e Dolz (2004) afirmam que o gênero é um instrumento mediador da experiência do indivíduo com o objeto sobre o qual ele age. Em outros termos, o gênero proporciona ao sujeito a possibilidade de ver o mundo de certa maneira e permite conhecimentos particulares sobre ele. Ele é artefato material ou simbólico existente fora do sujeito, mas pode ser utilizado em situações de ação, uma vez conhecidos os seus esquemas de utilização.

Para Dolz, Noverraz e Schneuwly (2004), os gêneros podem ser organizados tipologicamente em cinco ordenamentos: narrar, relatar, argumentar, expor e descrever ações. O narrar está situado no âmbito da cultura literária ficcional e na capacidade de linguagem dominante da mimese da ação através da criação da intriga no domínio do verossímil. O relatar, por sua vez, está situado no campo da documentação e memorização das ações humanas e na capacidade de linguagem dominante da representação pelo discurso de experiências vividas, situadas no tempo. O argumentar está na esfera da discussão de problemas sociais controversos e se relaciona com a capacidade de linguagem dominante de sustentação, refutação e negociação de tomadas de posição. É nesta ordem, portanto, que o artigo de opinião está localizado. O expor está situado no domínio da transmissão e construção de saberes e na capacidade de linguagem dominante da apresentação textual de diferentes formas dos saberes. Finalmente, o descrever ações está inserido no domínio das instruções e prescrições e na capacidade de linguagem dominante da regulação mútua de comportamentos. 
Muito embora Dolz, Noverraz e Schneuwly (2004) defendam que esses agrupamentos pareçam ser suficientemente diferentes uns dos outros, eles não descartam a hipótese de que há capacidades de produção de linguagem que atravessam os diferentes agrupamentos, e que isso não é levado em conta na proposta deles. Portanto, sugerem que os gêneros agrupados nessas tipologias devem compreender as seguintes capacidades de linguagem: mimese da ação através da criação da intriga no domínio do verossímil (narrar); representação pelo discurso de experiências vividas, situadas no tempo (relatar); sustentação, refutação e negociação de tomadas de posição (argumentar); apresentação textual de diferentes formas de saberes (expor); regulação mútua de comportamentos (descrever). Como podemos perceber, trata-se de um movimento de organização dos gêneros em função de certo quantitativo de regularidades linguísticas para definir capacidades globais a serem construídas ao longo da escolarização (DOLZ; NOVERRAZ; SCHNEUWLY, 2004, p. 60).

Uma vez definida a perspectiva de abordagem de gênero e tipologia textual, será dada continuidade à discussão com a conceituação e caracterização do gênero artigo de opinião.

\section{$2.2 \mathrm{O}$ gênero artigo de opinião e sua produção no contexto escolar}

Conforme sinalizamos, o artigo de opinião é um gênero da ordem do argumentar. A partir dele o articulista, especialista no assunto ou uma personalidade cuja opinião interessa a muitos, defende um ponto de vista sobre temas polêmicos que afetam a vida em sociedade. Entretanto, é preciso dizer que ele possui apenas certa liberdade de expressar sua opinião, pois os interesses políticos e econômicos da empresa jornalística em que o artigo circulará são priorizados, o que exige maior atenção do leitor ao analisar o que está sendo exposto. Interessa saber, ainda, que esse gênero é veiculado em jornais, revistas ou internet (GONÇALVES; HIGA, 2012; BRÄKLING, 2000, KAUFMAN; RODRIGUEZ, 1995).

A arquitetura textual do artigo de opinião é composta por: (1) identificação do tema em questão; (2) tomada de posição; (3) apresentação de argumentos para sustentar a tese e (4) reafirmação da posição adotada no início do texto. No que se refere às estratégias discursivas usadas para persuadir o leitor, merecem destaque: acusações claras aos oponentes, ironias, insinuações, digressões, apelações à sensibilidade, ou até mesmo 
a tomada de distância através do uso de construções impessoais para dar objetividade e consenso à análise realizada. $\mathrm{O}$ articulista pode optar, também, pela retenção do discurso em recursos descritivos ou em relatos em que as diferentes etapas da pesquisa estejam bem especificadas com uma minuciosa enumeração das fontes da informação. A progressão temática do artigo de opinião, por sua vez, ocorre geralmente através de um esquema de temas variados a partir dos quais são tecidos comentários do articulista (KAUFMAN; RODRIGUEZ, 1995).

Gonçalves e Higa (2012, p. 200) oferecem uma síntese do contexto de produção, bem como do conteúdo temático e do plano global do artigo de opinião, muito embora não tenham detalhado questões de estilo na escrita do referido gênero.

QUADRO 1 - Contexto de produção do artigo de opinião

\begin{tabular}{l|l}
\hline $\begin{array}{c}\text { Parâmetros do contexto de produção } \\
\text { do gênero artigo de opinião }\end{array}$ & \multicolumn{1}{c}{ Na esfera jornalística } \\
\hline Lugar social de produção & Numa instituição jornalística, por exemplo \\
\hline Enunciador (papel social do emissor) & $\begin{array}{l}\text { Jornalistas ou pessoas convidadas a produzir } \\
\text { artigos opinativos a respeito de uma temática de sua } \\
\text { especialidade }\end{array}$ \\
\hline Destinatário (papel social do receptor) & $\begin{array}{l}\text { Dirigido ao público leitor do jornal interessado no } \\
\text { tema, seja para apoiar ou recusar a tese defendida }\end{array}$ \\
\hline Objetivo da interação & $\begin{array}{l}\text { Provocar a reflexão sobre o tema e conduzir à tomada } \\
\text { de consciência/decisão/opinião; }\end{array}$ \\
\hline Circulação & Irrestrita, em tempos de internet \\
\hline
\end{tabular}

Fonte: Gonçalves e Higa (2012, p. 200)

O Quadro 1 explicita o contexto de produção do gênero artigo de opinião, pois o texto possui (1) objetivo; (2) enunciador; (3) destinatário; (4) lugar social de produção e, ainda, (5) suporte onde circula o referido gênero. Além do já exposto, explicita também o conteúdo temático (6) e o plano global do gênero (7). Essas são algumas das dimensões ensináveis do gênero na escola. É dessa forma que tal ferramenta deve embasar o trabalho do(a) professor(a), no contexto do ensino de língua, pois, sem eles, não há comunicação, muito menos trabalho sobre ela (SCHNEUWLY; DOLZ, 2004). 
Para Antunes (2009), um trabalho que envolva a proposta de ensinoaprendizagem de gêneros escritos, por exemplo, deve objetivamente ultrapassar os limites institucionais da escola, ter origens na corrente infinita dos muitos outros textos que circulam também fora dela. A autora, inclusive, destaca que a gênese do problema da escrita é justificada através da artificialidade dos contextos escolares em que a escrita é solicitada: ausência de dialogicidade, afastamento das propostas de produção escrita em relação aos usos sociais e, ainda, a estreiteza na compreensão das operações processuais implicadas na atividade de escrever.

Portanto, no trabalho com a produção do artigo de opinião, é preciso instrumentalizar o aprendiz para que ele possa descobrir, nas interações com seus pares, as determinações sociais das situações de comunicação, assim como o valor das unidades linguísticas no quadro de seu uso efetivo. Nesse contexto, as intervenções sistemáticas do(a) professor(a) desempenham um papel central para a transformação das interações entre o aprendiz e texto (DOLZ, 1994).

Com o objetivo de ampliar a discussão a respeito do trabalho com o artigo de opinião, apresentamos, a seguir, o conceito e as características do aspecto tipológico que mais se destaca no gênero artigo de opinião: a argumentação.

\subsubsection{A argumentação}

Argumentar é uma ação verbal na qual se utiliza a palavra oral ou escrita para defender uma tese, uma opinião, uma posição ou um ponto de vista particular a respeito de determinado fato. A argumentatividade, por sua vez, constitui o ato linguístico fundamental, pois em todo e qualquer discurso subjaz uma ideologia (KOCH, 2011).

Nessa mesma direção, Perelman e Olbrechts-Tyteca (1996) afirmam que o ato de argumentar apoia-se em duas técnicas: a persuasão no campo da subjetividade e o convencimento no campo da objetividade. Então, primeiro utilizamos a técnica do convencimento com base na ética e, em seguida, utilizamos a persuasão, com o intuito de seduzir o outro através das emoções.

É válido lembrar que quem se inquieta com a eficácia do ato de argumentar prioriza a persuasão. Para convencer, o(a) usuário(a) se utiliza de uma argumentação lógica, mediada por uma comprovação objetiva e bastante óbvia que, se desvinculada da persuasão, torna-se improdutiva para 
a adesão dos interlocutores àquilo que se apresenta como tese (REIZÁBAL apud PASSARELLI, 2012).

Para Koch (2011), as marcas linguísticas da argumentação são: as pressuposições, as marcas das intenções, os modalizadores que revelam sua atitude perante o enunciado que produz, os operadores argumentativos e as imagens recíprocas que se estabelecem entre os interlocutores(as) e as máscaras por eles(as) assumidas no jogo de representações.

No que se refere ao esquema argumentativo, Toulmin (2001) oferece um modelo didático sintético da estrutura do argumento.

QUADRO 2 - A estrutura do argumento

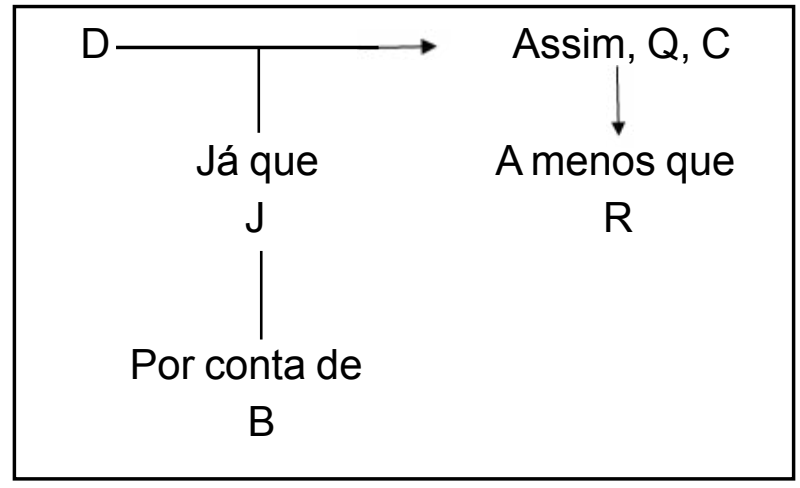

Fonte: Toulmin (2001)

Segundo o autor, D é o conjunto de dados que o argumentador toma como ponto de partida para o seu raciocínio. C é a conclusão a qual o argumentador quer chegar. J é o conjunto de justificativas ou argumentos que o argumentador reúne e analisa, com o objetivo de sustentar a conclusão ou tese. B é o suporte ou o conjunto de informações complementares que ajudam o argumentador a reforçar os dados e fatos de que parte ou, ainda, as justificativas/argumentos que apresenta. Q é o modalizador, palavra ou expressão por meio da qual o argumentador expressa determinada atitude em relação à conclusão proposta - que ele espera ser aceita pelo leitor. Finalmente, R é a refutação, somente citada para mostrar como e por que não procede.

Além dos aspectos apontados, temos que nos lembrar de que a intertextualidade é, também, importante estratégia argumentativa, visto que 
o intertexto funciona como argumento de autoridade e/ou gancho para discussão de temas (KOCH; ELIAS, 2016).

Em se tratando do artigo de opinião, é necessário que, além de considerarmos todos esses elementos que constituem a dimensão argumentativa no processo de ensino-aprendizagem do gênero, devemos considerar a existência da construção de significados compartilhados entre os interlocutores, de forma que os indivíduos possam expandir seu ponto de vista e reconstruí-lo interdependentemente (LIBERALI, 2013).

Com base nessa costura teórica, estabelecemos a análise dos dados. Porém, antes de apresentarmos esse diálogo, detalhamos, a seguir, os procedimentos metodológicos adotados para a realização deste trabalho.

\section{Metodologia}

Conforme sinalizamos, neste estudo investigamos a didatização do gênero artigo de opinião na coleção de livro didático Português: contexto, interlocução e sentido, com vistas a identificar as estratégias de ensino do gênero artigo de opinião e refletimos sobre a proposta da obra para o seu processo de ensino-aprendizagem. O livro didático, portanto, é tomado para exame, o que configura um procedimento de análise documental, técnica que consiste na reunião e descrição do conteúdo dos documentos e implica a possibilidade de "efetuar uma primeira ordenação das informações para selecionar aquelas que parecem pertinentes" (LAVILLE; DIONNE, 1999, p. 168).

O corpus de investigação é constituído por elementos do capítulo 27, unidade 8, identificada como "Artigo de opinião e editorial", da obra Português: contexto, interlocução e sentido (volume 2), de autoria de Maria Luiza M. Abaurre, Maria Bernadete M. Abaurre e Marcela Pontara, e publicada pela Editora Moderna no ano de 2013. Justificamos a escolha desse material didático pelo fato de que, segundo a avaliação do Guia de Livros Didáticos: PNLD 2015 (BRASIL, 2014), a coleção distingue-se das demais por ter como foco principal a perspectiva discursiva de tratamento dos diversos eixos do ensino de LP, além da correção e atualização dos princípios teóricos que embasam o trabalho com eles.

Para realizarmos a análise dos dados, utilizamos dimensões da técnica de análise de conteúdo categorial definidos por Bardin (2009). Este método conduz a descrições e interpretações qualitativas e sistemáticas de diversos 
tipos de documentos e textos (BARDIN, 2009). Sob essa lente teórica, organizamos as informações de acordo com os temas: concepção de gênero adotada e abordagem de questões sobre gênero; objetivos da proposta; conceituação do gênero ou reflexão sobre ele (contextualização, plano global e questões de estilo) e, ainda, atividade de produção textual. A partir desta organização, pudemos alcançar os objetivos traçados para este artigo, com vistas a alcançar os objetivos traçados para este artigo.

Vejamos, a seguir, a análise dos dados, embasados na teoria de sustentação anunciada e nos critérios analíticos acima descritos.

\section{Artigo de opinião no livro didático de língua portuguesa: reflexões analíticas}

Inicialmente gostaríamos de situar o(a) leitor(a) sobre a estratégia de organização da obra para tratar do artigo de opinião. Este gênero é inserido na unidade 8, em que discorre sobre os gêneros da ordem do argumentar. Interessa saber que - antes de iniciar o trabalho -, no capítulo anterior, as autoras apresentaram uma proposta de ensino com o gênero carta aberta. Merece destaque o fato de que elas oferecem ao(a) aluno(a) uma pequena exposição sobre o que é a argumentação na apresentação da unidade, em que sinalizam a natureza da argumentação e sua importância social, conforme podemos observar no fragmento a seguir: "A argumentação vem sempre associada a um desafio: convencer alguém de alguma coisa, demonstrar a validade de uma tese, defender um ponto de vista. Cada uma dessas finalidades se manifestará, em maior ou menor grau, nos gêneros discursivos apresentados nesta unidade" (ABAURRE; ABAURRE; PONTARA, 2013, p. 373).

No que diz respeito à concepção de gênero adotada e à abordagem de questões sobre o gênero, as autoras evidenciam que a abordagem privilegia a dimensão enunciativo-discursiva, defendida por Bakhtin (1997) e, preferencialmente, prestigiada pelo PNLD (2015).

Do mesmo modo, logo no início do capítulo são explicitados os objetivos que as autoras esperam que os(as) alunos(as) alcancem. São eles que ratificam que serão trabalhados dois gêneros conforme anunciado no título do capítulo "Artigo de opinião e editorial". Vejamos os objetivos: 
(1) reconhecer as características estruturais do artigo de opinião e do editorial; (2) identificar a finalidade destes gêneros discursivos; (3) compreender de que modo o contexto de circulação e o perfil do interlocutor afetam a estrutura de ambos os gêneros; (4) saber escolher os recursos estilísticos adequados a cada um deles (5) diferenciar um artigo de opinião de um editorial; (6) compreender a importância dos contra-argumentos como estratégia argumentativa (ABAURRE; ABAURRE; PONTARA, 2013, p. 383).

É válido salientar que tais objetivos dialogam com as competências de área 1 e 7 exigidas na Matriz de Referência do Exame Nacional do Ensino Médio (BRASIL, 2012, p. 2-4), que dizem respeito, respectivamente, a "aplicar as tecnologias da comunicação e da informação na escola, no trabalho e em outros contextos relevantes para a sua vida [a vida do aluno]" e "confrontar opiniões e pontos de vista sobre as diferentes linguagens e suas manifestações específicas".

Os objetivos da obra dialogam também com as habilidades - a seguir indicadas - na referida Matriz. São elas:

Identificar as diferentes linguagens e seus recursos expressivos como elementos de caracterização dos sistemas de comunicação (H1).

Recorrer aos conhecimentos sobre as linguagens dos sistemas de comunicação e informação para resolver problemas sociais (H2).

Relacionar informações geradas nos sistemas de comunicação e informação, considerando a função social desses sistemas (H3).

Reconhecer posições críticas aos usos sociais que são feitos das linguagens e dos sistemas de comunicação e informação (H4).

Relacionar, em diferentes textos, opiniões, temas, assuntos e recursos lingüísticos (H22).

Inferir em um texto quais são os objetivos de seu produtor e quem é seu público alvo, pela análise dos procedimentos argumentativos utilizados (H23).

Reconhecer no texto estratégias argumentativas empregadas para o convencimento do público, tais como a intimidação, sedução, comoção, chantagem, entre outras (H24) (BRASIL, 2012, p. 2-4). 
Na obra, a abordagem do gênero é iniciada através da proposta de leitura do artigo de opinião "Os porquinhos vão à praia", 2 de Ruth de Aquino, publicado na Revista Época. Neste texto, são feitas algumas supressões de conteúdo, como a imagem da articulista e alguns argumentos secundários. As autoras começam a explorar na seção "Análise” os pressupostos teóricos da sequência argumentativa. Vejamos.

FIGURA 1 - Questões sobre a argumentação, no artigo de opinião escrito por Ruth de Aquino

\section{Analise}

1. Qual é a questão central abordada por Ruth de Aquino?

2. Qual foi o fato que chamou a atenção da autora para o problema abordado?

a) Segundo ela, a responsabilidade por esse problema pode ser atribuída somente à Comlurb? Justifique.

b) Transcreva no seu caderno o trecho em que a autora utiliza uma metáfora para mostrar que a origem do problema pode ser associada à educação familiar.

3. Por que podemos afirmar que a pergunta "Que direito tem a prefeitura de expor nossa falta de respeito com o espaço público?" deve ser interpretada de modo irônico?

- Transcreva no seu caderno a passagem do texto em que a autora deixa explícita sua opinião sobre as consequências positivas da falha operacional da Comlurb.

4. Com relação ao problema apontado, qual é a posição defendida pela autora?

5. Releia o 60 parágrafo. Ele evidencia uma estratégia adotada pela autora para convencer os leitores da posição que defende. Qual é essa estratégia?

a) Segundo ela, como "os porquinhos" justificariam seu comportamento?

b) Quais são os contra-argumentos apresentados por Ruth de Aquino?

c) A estratégia utilizada por ela pode influenciar a opinião dos leitores do texto? Explique.

6. Várias perguntas são feitas nos dois últimos parágrafos do texto. Após reler esses dois parágrafos, responda: que função elas cumprem na estrutura argumentativa criada pela autora?

Fonte: Abaurre; Abaurre; Pontara (2013, p. 384-385)

${ }^{2}$ Disponível em: https://glo.bo/2HINn9C. Acesso em: 30 mai. 2017 
Podemos observar que, na proposta, são introduzidas aos alunos(as) questões sobre o problema, tese, argumentos que sustentam a opinião e, ainda, estilo empregado na construção do texto de Ruth de Aquino. É pertinente pontuar, também, que os(as) alunos(as) são instigados a refletir sobre os contra-argumentos oferecidos pela articulista. Assim, são apresentadas estratégias didáticas que podem, possivelmente, corroborar a aprendizagem significativa da sequência argumentativa na construção do artigo de opinião.

É válido destacarmos que, na medida em que as autoras apresentam a funcionalidade da contra-argumentação, afirmando que "tal estratégia faz com que o autor pareça uma pessoa ponderada, capaz de analisar diferentes pontos de vista [...]" (ABAURRE; ABAURRE; PONTARA, 2013, p. 385), esta estratégia didática também desenvolve competências e habilidades inerentes ao confronto de opiniões e, portanto, a análise de diferentes pontos de vista.

Os(as) alunos(as) são convidados, ainda, a refletirem sobre os usos linguísticos feitos por Ruth de Aquino no texto "Os porquinhos vão à praia", uma vez que os aspectos discursivos e notacionais do gênero artigo de opinião são discutidos ao longo do capítulo. É válido lembrar que, inicialmente, não é oferecido um conceito pronto sobre o gênero e sua estrutura. Somente após o trabalho com texto as autoras oferecem uma reflexão sobre o assunto, na subseção "Tome nota", da seção "Artigo de opinião: definição e usos" (ABAURRE; ABAURRE; PONTARA, 2013, p. 385). Vejamos a seguir:

FIGURA 2 - Conceituação do gênero textual artigo de opinião

\section{Tome nota}

0 artigo de opinião é um gênero discursivo claramente argumentativo que tem por objetivo expressar o ponto de vista do autor que o assina sobre alguma questão relevante, geralmente controversa, de natureza social, política, cultural, etc. 0 caráter argumentativo do texto de opinião é evidenciado pelas justificativas de posições arroladas pelo autor para convencer os leitores da validade da análise que faz.

Fonte: Abaurre; Abaurre; Pontara (2013, p. 385) 
Nesta seção, as autoras apresentam informações sobre a esfera de circulação do gênero, bem como a sua finalidade e suporte em que ele é publicado. No conteúdo da Figura 2, é possível perceber que as autoras oferecem uma definição objetiva do gênero artigo de opinião. Entretanto, a linguagem utilizada na definição parece se distanciar um pouco do(a) aluno(a), que possivelmente pode não compreender com clareza o que são questões controversas, tampouco saber identificar o caráter argumentativo de um texto ou, ainda, significado da palavra "arrolar". As autoras também não recuperam a reflexão anterior sobre o estudo do texto de Ruth de Aquino. Desse modo, a conceituação parece ficar solta em meio a uma tentativa de construção progressiva de conhecimento.

Em contrapartida, é válido ressaltar a preocupação das autoras em situar, para o estudante, o contexto de produção desse gênero, sua funcionalidade e características estruturais com riqueza de detalhes. Para isso, o obra se ancora em veículos de informação conhecidos pelos(as) jovens(as), como o jornal Folha de S. Paulo, e também na experiência de notáveis articulistas, como Roberto Pompeu de Toledo, que "não tem receio de manifestar claramente seus pontos de vista sobre questões polêmicas" (ABAURRE; ABAURRE; PONTARA, 2013, p. 386). Assim, as autoras atendem a competência número um da Matriz de referência do ENEM, bem como os pressupostos teóricos defendidos por Marcuschi (2008), Antunes (2009), Gonçalves e Higa (2012) e Lopes-Rossi (2011), que defendem que o(a) aluno(a) precisa ver sentido nas aulas de português, começando por encontrar relação entre o que ele aprende na escola e seu cotidiano.

É assim que está sistematizada a exposição teórica do gênero textual artigo de opinião: conceituação, contexto de circulação, leitores(as) do texto, estrutura e linguagem. A mesma organização é feita com relação ao gênero textual editorial, como se pode observar nas páginas 389-393, novo gênero que as autoras apresentam no mesmo capítulo com a justificativa de que, "além dos artigos assinados em que um(a) articulista apresenta sua opinião sobre importantes acontecimentos contemporâneos, os jornais também são o espaço de circulação de um outro gênero argumentativo, encarregado de explicitar a posição do próprio veículo de comunicação: o editorial [...]" (ABAURRE; ABAURRE; PONTARA, 2013, p. 389).

Como é perceptível, a obra trata de dois gêneros próximos (no que se refere à funcionalidade), entretanto, um pouco distantes (no que se refere 
ao contexto de produção e ao estilo), o que pode prejudicar o progresso do trabalho que estava sendo desenvolvido, uma vez que poderia ser mais adequada, na sequência da proposta didática, a proposição da produção de um artigo de opinião e não a apresentação de mais um gênero - quando o trabalho com o anterior ainda não havia sido totalmente concluído.

Ainda em relação à apresentação de alguma conceituação do gênero ou reflexão sobre ele, na seção "Contexto de circulação", é possível que os(as) alunos(as) saibam em quais suportes os artigos de opinião circulam: "colunas assinadas dos jornais diários e revistas semanais, que costumam contar com um quadro fixo de articulistas.", bem como "grandes portais de notícia da internet." (ABAURRE; ABAURRE; PONTARA, 2013, p. 386), e compreendam a importância do conhecimento do público leitor pelo articulista, pois "a capacidade analítico-argumentativa de seus autores costuma conquistar leitores fiéis para os veículos que os publicam." (ABAURRE; ABAURRE; PONTARA, 2013, p. 386). Essas colocações das autoras dialogam com a afirmação de Rangel, Gagliardi e Amaral (2014), segundo os quais é o conhecimento sobre o público leitor que impulsiona a seleção de argumentos e contra-argumentos eficientes para sustentação da tese defendida pelo(a) articulista. É válido destacar que, nesta seção, as autoras fizeram referência ao trabalho com o texto de Ruth de Aquino que iniciou a didatização do gênero, ao afirmarem que algumas colunas, nas quais os artigos são publicados, já se tornaram "marca registrada" de determinadas revistas, como é o caso da seção "Mente aberta" da Revista Época - na qual os textos de Ruth de Aquino são publicados.

$\mathrm{Na}$ seção seguinte, intitulada "Os leitores do artigo de opinião", as autoras ratificam o caráter dialógico do artigo de opinião ao explicitarem a cumplicidade entre o(a) articulista e público leitor. Todavia, diferentemente da seção anterior, não há nenhuma referência ao texto-base. Por outro lado, a atitude das autoras de registrar no processo de didatização do gênero a relevância de elementos do contexto - como enunciador e destinatário (GONÇALVES; HIGA, 2012) - dialoga com os pressupostos teóricos defendidos por Antunes (2009), que defende a importância de o(a) escritor(a) de textos conhecer seu leitor/ouvinte.

É pertinente ressaltar, ainda, que as autoras ilustram a seção com a carta de um leitor dos textos escritos por Roberto Pompeu de Toledo, que externa a fascinação que sente pela capacidade do articulista de transmitir um ponto de vista sobre um assunto "com clareza e exatidão de ideias, que, 
convenhamos, são sempre procedentes, inteligentes e precisas. [...]" (Veja apud ABAURRE; ABAURRE; PONTARA, 2013, p. 386). Chama atenção o enfoque dado ao trabalho do articulista Paulo Francis, famoso por atrair leitores(as) que concordavam com suas posições radicais, bem como aqueles que delas discordavam. Isso pode contribuir para o conhecimento mais aprofundado dos(as) alunos(as) sobre o contexto de produção de artigo de opinião e, até mesmo, o plano global do referido gênero, uma vez que o discente pode passar a entender que a forma como os(as) articulistas(as) escreviam seus textos podia servir como dica para a produção de artigos de opinião.

$\mathrm{Na}$ seção estrutura, as autoras desmistificam a ideia de que deva existir uma estrutura fixa de produção do gênero artigo de opinião. Todavia, ressaltam que ele "precisa contar com partes que desempenham determinadas funções". (ABAURRE; ABAURRE; PONTARA, 2013, p. 386). Assim, iniciam um detalhamento do papel da introdução, do desenvolvimento e da conclusão do texto "Lições de Virgínia Tech", de autoria de Nelson Ascher, publicado no jornal Folha de S. Paulo. Com isso, pode ficar claro para os(as) alunos(as) que são essas as partes imprescindíveis ao alcance do objetivo comunicativo do artigo de opinião.

Nos comentários feitos ao lado de cada parágrafo do artigo de opinião de autoria de Nelson Ascher, merecem destaque as seguintes colocações:

Título: antecipa para o leitor a questão que será analisada no texto [...] Subtítulo: explicita a perspectiva analítica que será defendida pelo autor. [...]. O autor do subtítulo não costuma ser o articulista, e sim o editor do jornal ou revista em que o texto será publicado.

$1^{\circ}$ parágrafo: contextualização da questão que será analisada $[. .$.$] .$

$2^{\circ}$ parágrafo: início da análise do autor, marcada pelo uso de termos que expressam juízos de valor. [...]

$3^{\circ}$ e $4^{\circ}$ parágrafos: as respostas que começam a ser apresentadas conduzem o leitor, passo a passo, pelo raciocínio analítico do autor, favorecendo sua aceitação das conclusões apresentadas, porque acompanha a análise desenvolvida pelo autor. [...] a mesma estrutura será mantida no $4^{\circ}$ parágrafo. 
$7^{\circ}$ e $8^{\circ}$ parágrafo: (conclusão): os parágrafos finais trazem a explicitação da análise do articulista para defender sua tese (antecipada, no subtítulo, pelo editor) - cada indivíduo, consideradas sua perspectiva ideológica e suas convicções pessoais, vai encontrar uma explicação diferente, "que faça sentido na sua visão mais ampla de mundo". (ABAURRE; ABAURRE; PONTARA, 2013, p. 387-388).

A partir dos comentários feitos pelas autoras, é perceptível que elas objetivam oferecer mais detalhes sobre o conteúdo temático, plano global do artigo de opinião e também estilo. Para isso, tecem considerações sobre o título e se prolongam até a conclusão do texto. Isso consiste em uma estratégia válida de didatização do gênero artigo de opinião, indo além de teorizações infrutíferas do ponto de vista da produção de artigo de natureza opinativa. Com esse encaminhamento, a obra caminha na perspectiva - de Oliveira (2010) e Costa e Salces (2013) - de que é preciso orientar os(as) educandos(as) quanto ao processamento didático da construção de gêneros.

Consideramos pertinentes as considerações a respeito do papel do título e do subtítulo no artigo, bem como a explicitação a respeito da importância da contextualização da discussão que deve ser feita no primeiro parágrafo para, só a partir de então, ser iniciado o processo de análise do problema para o qual se procura apontar uma possível solução. Ressalta-se, ainda, que - em meio às considerações das autoras - chama atenção também o destaque para o uso de adjetivos e advérbios na formulação de julgamentos de valor pelo articulista, o que é característico do segundo parágrafo do texto. A partir de então, são oferecidos argumentos que darão sustentação para a tese ratificada no(s) último(s) parágrafo(s).

O detalhamento feito pelas autoras na seção "Estrutura" dialoga com a literatura sobre o esquema da argumentação oferecido por Toulmin (2001), em que os dados, a conclusão e a justificativa compõem o núcleo de uma argumentação. Muito embora este não seja o único esquema para analisar a estrutura de textos da ordem do argumentar, ele favorece a compreensão, por parte dos(as) educandos(as), de que cada parte do texto que apresenta características do gênero artigo de opinião desempenha uma função importante para o alcance do objetivo principal deste texto: discorrer sobre temas polêmicos de interesse coletivo.

Nesta altura da discussão, ainda é conveniente afirmarmos que as colocações feitas pelas autoras sobre o registro e estratégias argumentativas 
também são confirmadas por Reizábal (apud PASSARELLI, 2012) ao afirmar que o ato de argumentar está baseado em duas técnicas: persuasão no campo da subjetividade e convencimento no campo da objetividade. Estas ajudam os(as) alunos(as) a se inteirar dos usos linguísticos que regularmente compõem textos da ordem do argumentar, especialmente o artigo de opinião. Portanto, a estratégia de revisar a estrutura do artigo em suas dimensões sintática, semântica e pragmática pode contribuir para o conhecimento e a produção do gênero.

Após discorrerem sobre os aspectos sociodiscursivos do gênero, as autoras direcionaram o olhar delas para os aspectos linguísticos e estruturais, o que dialoga com Schneuwly e Dolz (2004) e também Santos (2007), que afirmam ser importante a realização de ações didáticas que representem as propriedades constituintes dos gêneros (os aspectos sociodiscursivos, linguísticos e estruturais) da forma mais aproximada possível, sem perder de vista a dinâmica de ensino-aprendizagem da própria escola.

Nesse sentido, na seção "Linguagem", as autoras contextualizam a produção do gênero quando afirmam que o suporte em que ele será veiculado e o perfil dos possíveis leitores(as) influenciam no grau de formalidade do texto. Por esse ângulo, é possível gerar a compreensão de que, na produção do gênero artigo de opinião, a imagem do(a) leitor(a) e o suporte são fatores decisivos para a escolha do grau de formalidade da linguagem empregada na construção do texto, muito embora seja geralmente recomendável o uso da escrita orientada pela norma urbana de prestígio na produção de textos para jornais e revistas. Dessa forma, os(as) alunos(as) são informados(as) que a materialidade linguística do artigo de opinião "admite a expressão de uma perspectiva mais subjetiva, ainda que 'controlada' pelo forte teor argumentativo desse gênero." Entretanto, elas ressaltam que "é recomendável que autores menos experientes tentem evitar esses comentários mais informais, para não comprometerem a estrutura argumentativa do texto que estão escrevendo." (ABAURRE; ABAURRE; PONTARA, 2013, p. 389). Para ilustrar essa situação, as autoras retomam trechos do primeiro artigo de opinião utilizado na proposta de didatização: "Os porquinhos vão à praia”, escrito por Ruth de Aquino. 
FIGURA 3 - A linguagem do artigo de opinião escrito por Ruth de Aquino [...] Os guardas municipais raramente abordam os sujismundos e preferem tentar
educar, explicar que não é legal.
[...]. Ou você se sente incapaz de jogar qualquer coisa no chão e anda com o papel
melado de bala até encontrar uma lixeira, ou você joga mesmo, sem culpa nem perdão.

Fonte: Abaurre; Abaurre; Pontara (2013, p. 388)

Como é possível constatar nos excertos acima, Ruth de Aquino faz uso um pouco menos formal da linguagem, o que revela uma perspectiva mais subjetiva de produção do texto. Todavia, a materialidade do discurso não deixa de ser argumento. E, após discorrer sobre a linguagem, as autoras encerram a discussão sobre o gênero artigo de opinião.

No que se refere à relação entre as atividades de produção textual e o trabalho anterior, a proposta de produção do capítulo não é com o artigo de opinião, mas com o gênero editorial, o que compromete a didatização do primeiro, pois, se os aspectos discursivos e notacionais vinham sendo conduzidos de forma progressiva, o que se esperava era que as autoras apresentassem uma proposta de produção do gênero. Porém, isso efetivamente não aconteceu. O cenário sugere que todo o esforço investido anteriormente foi desconsiderado no momento que a produção não enfocou o artigo de opinião. É preciso reiterar que somente a proposta de produção do gênero editorial foi apresentada com maior detalhamento do contexto de produção do texto, do plano global do texto, o que inclui a estratégia argumentativa, a contra-argumentação e, ainda, o estilo.

Há uma proposta de produção de artigo de opinião apenas na seção "Enem, outras avaliações oficiais e vestibulares". Porém, as recomendações para a produção parecem ser insuficientes, conforme é possível observar no fragmento a seguir: 


\section{FIGURA 4 - Proposta de produção de artigo de opinião}

\section{Enem, outras avaliações oficiais e vestibulares}

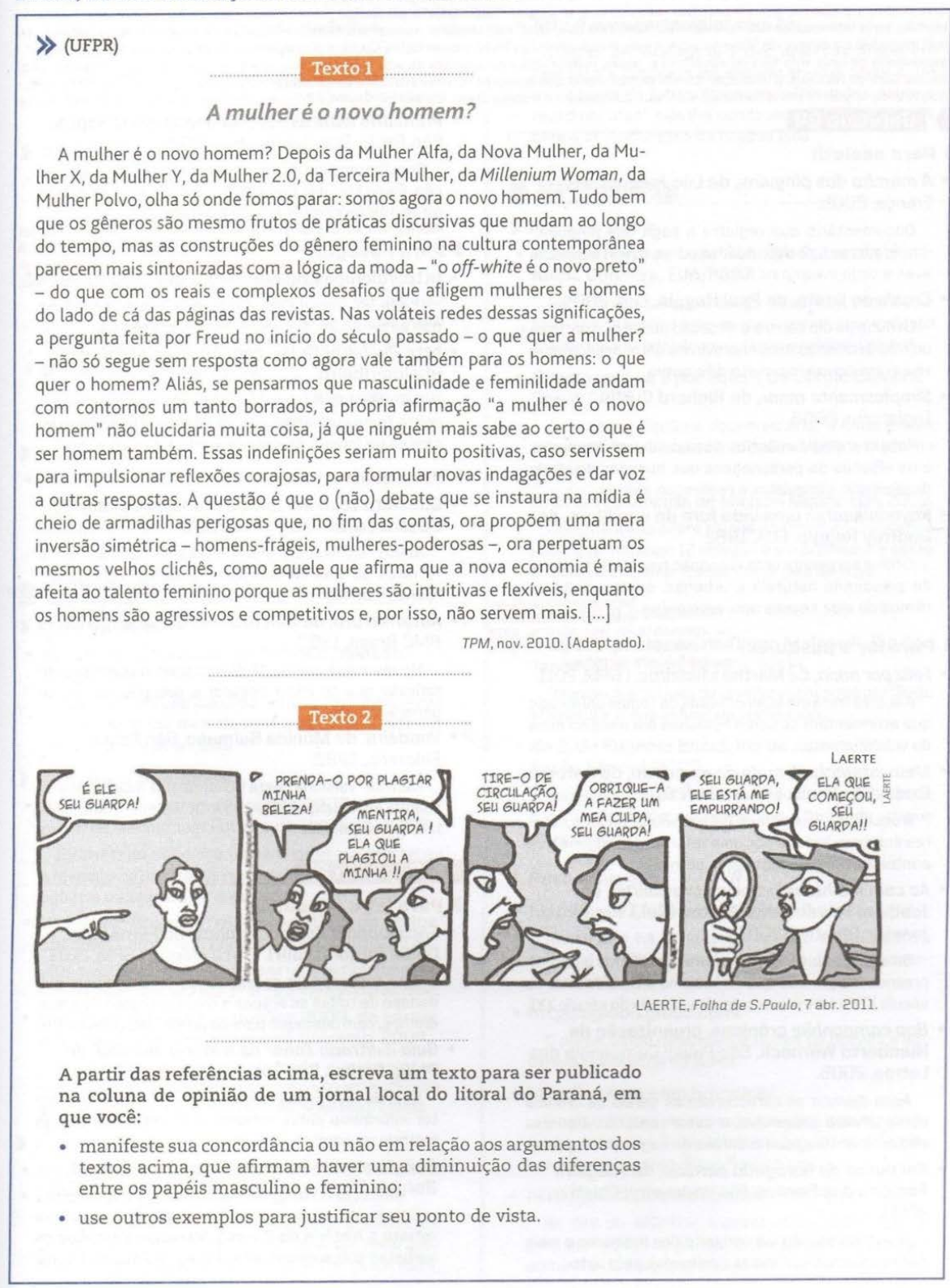

Fonte: Abaurre; Abaurre; Pontara (2013, p. 395) 
Como visto, a proposta parece não fornecer subsídios para a compreensão da atividade de produção e para o contexto de produção do texto. É válido ressaltar que, se o(a) professor(a) não tiver autonomia para conduzir a atividade de forma adequada, será esse o trabalho realizado em sala de aula e, consequentemente, quem irá ser prejudicado nesse processo é o aluno.

Muito embora a autoria da atividade não seja de Maria Luiza M. Abaurre, Maria Bernadete M. Abaurre e Marcela Pontara, a proposta de produção de artigo de opinião carece de maiores detalhes, como informações do contexto, plano global e estilo, pois, embora o Texto 1 seja motivador para a produção do gênero, é preciso destacar que ele não é apresentado na íntegra, tampouco o nome do autor é informado. É conveniente dizermos, também, que a tirinha de Laerte endossa a discussão, trazendo à baila a ditadura da beleza de ambos os sexos (masculino e feminino). Mas, a nosso ver, é insuficiente apresentar na proposta de produção apenas os comandos "manifeste sua concordância ou não em relação aos argumentos dos textos acima, que afirmam haver uma diminuição das diferenças entre os papéis masculino e feminino:"; e, além disso, solicitar que o(a) aluno(a) "use outros exemplos para justificar seu ponto de vista." (ABAURRE; ABAURRE; PONTARA, 2013, p. 395).

Portanto, é conveniente afirmar que na abordagem didática do artigo de opinião parece não existir um elo entre as diferentes partes do capítulo. Essa mesma problemática também foi constatada por Guimarães (2003) ao revelar que alguns livros didáticos de Língua Portuguesa ainda apresentam proposta de ensino descontextualizada ou uma visão fragmentada de seus conteúdos. Nesse sentido, seria interessante que as autoras articulassem as diferentes seções do capítulo, recuperando as discussões anteriores e anunciando as que seguem.

\section{Considerações finais}

Neste trabalho, investigamos a didatização do gênero artigo de opinião na coleção de livro didático Português: contexto, interlocução e sentido. De modo específico, identificamos as estratégias de ensino do gênero artigo de opinião e refletimos sobre a proposta da obra para o seu processo de ensino-aprendizagem. 
Então, perseguindo nossos objetivos, podemos afirmar que a abordagem do gênero textual artigo de opinião no volume 2 da coleção Português: contexto, interlocução e sentido poderia ter sido feita de forma mais didática, uma vez que algumas seções do capítulo (como a seção "Artigo de opinião: definições e usos") ainda apresentam linguagem distante do(a) aluno(a), além de não resgatar o conhecimento construído em seções anteriores do capítulo - o que sabemos que é de suma importância na construção da aprendizagem significativa - não somente na área de Linguagens -, porque nossos(as) alunos(as) precisam construir com seu professor(a) o conceito do gênero e entender como ele é construído através do contato com modelos do gênero em estudo. E, nesse contexto, se o livro didático, que muitas vezes é a porta para o conhecimento desses textos, traz uma abordagem fragmentada ou desarticulada com uma proposta de aprendizagem significativa, será o(a) aluno(a) o prejudicado nesse processo. Assim, defendemos que um caminho possível para mediação de gêneros é a apresentação de modelos destes, seguida da sistematização e análise de seus aspectos discursivos e notacionais.

Além disso, o texto de Ruth de Aquino tratado na obra poderia ter sido apresentado na íntegra, porque, quando são retiradas as caraterísticas do texto da forma como ele circula socialmente, descaracteriza-se o referido texto como prática social comunicativa e escolariza-se a sua recepção, o que dá margem à construção de uma imagem do texto como algo encerrado no contexto escolar, e não como instrumento de ação no mundo - e, portanto, de participação efetiva nas decisões que afetam o tecido social. Portanto, defendemos a pertinência da manutenção das caraterísticas do gênero da forma como ele circula socialmente como gancho para apropriação cultural.

No que se refere à proposta de produção textual envolvendo o gênero artigo de opinião, acreditamos que ela poderia ter sido detalhada de forma precisa, pois na proposta ofertada no capítulo não são fornecidos direcionamentos necessários para que os(as) alunos(as) se inteirem do contexto de produção do texto, seu plano global e, ainda, questões de estilo. Desse modo, perpetua-se a artificialidade dos contextos escolares em que a escrita é solicitada. Diante desse problema, reiteramos a necessidade de especialmente os(as) professores(as) de Língua Portuguesa contextualizarem as propostas de produção de textos de seus alunos(as); e, mais do que isso, conferirem a essas produções o status de redações miméticas (aquelas que 
mais se aproximam da prática social efetiva), proporcionando, por exemplo, a circulação desses textos para além dos muros da escola.

É pertinente destacar, também, as estratégias presentes na obra que podem favorecer a produção do gênero, como por exemplo: a estratégia de construção progressiva do conceito do gênero; a abordagem de sua funcionalidade e sua estrutura; ilustração de exposições teóricas através de informações de veículos que publicam artigos de opinião; informações sobre a experiência de articulistas de destaque nacional, como Roberto Pompeu de Toledo, Paulo Francis, Élio Gaspari, Miriam Leitão, bem como Ruth de Aquino. É pertinente, também, a estratégia de análise do artigo de opinião intitulado "Lições de Vírginia Tech" - de autoria de Nelson Ascher - e, ainda, o uso, mesmo que de forma pontual, de trechos do texto de Ruth de Aquino, na seção "Contexto de circulação e Linguagem”.

É válido ressaltar, porém, que o livro didático não substitui o(a) professor(a) e toda sua experiência, e, do mesmo modo, que o fato de um material de apoio pedagógico estar na mão de todos(as) os(as) alunos(as) não deve impedir que $\mathrm{o}(\mathrm{a})$ professor(a) procure outras fontes de informação para dinamizar e enriquecer - ainda mais - o seu trabalho com a língua materna.

\section{Contribuição dos autores}

Lenilton Junior contribuiu com a proposta de trabalho, bem como com o desenvolvimento das diferentes seções que o compõem. Débora Amorim Gomes da Costa-Maciel contribuiu com os últimos ajustes no corpo do texto, bem como com algumas sugestões relacionadas à qualidade de imagens e tabelas.

\section{Referências}

ABAURRE, M. L. M.; ABAURRE, M. B. M.; PONTARA, M. Português: contexto, interlocução e sentido. 2. ed. São Paulo: Moderna, 2013. v. 2.

ALBUQUERQUE, E. B. C.; FERREIRA, A. T. B. Programa Nacional de livro didático (PNLD): mudanças nos livros de alfabetização e os usos que os professores fazem desse recurso em sala de aula. Ensaio: Avaliação de Política Pública Educacional, Rio de Janeiro, v. 27, n. 103, p. 250-270, 2019. Doi: https://doi.org/10.1590/ s0104-40362019002701617. Disponível em: https://bit.ly/2YRRA0z. Acesso em: 28 abr. 2019. 
ANTUNES, I. Lingua, texto e ensino: outra escola possível. São Paulo: Parábola Editorial, 2009.

ANTUNES, I. Aula de português. encontro e interação. São Paulo: Parábola Editorial, 2003.

BAKHTIN, M. Os gêneros do discurso. In: BAKHTIN, M. Estética da criação verbal. São Paulo: Martins Fontes, 1997.

BARDIN, L. Análise de conteúdo. São Paulo: Edições 70, 2009.

BRÄKLING, K. L. Trabalhando com o artigo de opinião: revisitando o eu no exercício da palavra do outro. In: ROJO, R. (org.). A prática da linguagem na sala de aula: praticando os PCNs. Campinas: Mercado de Letras, 2000.

BRASIL. Ministério da Educação. Secretaria de Educação Básica. Base Nacional Comum Curricular. Brasília: Ministério da Educação: MEC/SEB, 2017.

BRASIL. Ministério da Educação. Secretaria de Educação Básica. Guia de livros didáticos: PNLD 2015: língua portuguesa: ensino médio. Brasillia, DF: MEC/SEB, 2014.

BRASIL. Ministério da Educação. Diretrizes Curriculares Nacionais da Educação Básica. Brasília, DF: MEC/SEB/DICEI, 2013.

BRASIL. Ministério da Educação. Instituto Nacional de Estudos e Pesquisas Educacionais Anísio Teixeira. Matriz de Referência ENEM. Brasília, DF: MEC/ INEP, 2012.

BRASIL. Ministério da Educação. Secretaria de Educação Fundamental. Parâmetros Curriculares Nacionais: Ensino Fundamental: Língua Portuguesa. Brasília, DF: MEC/ SEF, 1998.

BRONCKART, J.-P. Atividade de linguagem, discurso e desenvolvimento bumano. Tradução de Anna Rachel Machado e Maria de Lourdes Meirelles Matêncio. Campinas: Mercado de Letras, 2006.

BRONCKART, J.-P. Atividade de linguagem, textos e discursos: por um interacionismo sociodiscursivo. Tradução de Anna Rachel Machado e Péricles Cunha. São Paulo: EDUC, 1999.

BUNZEN, C. O antigo e o novo testamento: livro didático e apostila escolar. Revista ao Pé da Letra, Recife, v. 3, n. 1, p. 35-46, 2001. Disponível em: < https://periodicos. ufpe.br/revistas/pedaletra/article/view/231468/0> Acesso em: 8 set. 2018.

COSTA, D. C. L.; SALCES, C. D. Leitura e produção de textos na Universidade. Campinas: Editora Alínea, 2013. 
DOLZ, J.; NOVERRAZ, M.; SCHNEUWLY, B. Sequências didáticas para o oral e a escrita: apresentação de um procedimento. In: SCHNEUWLY, B; DOLZ, J. Gêneros orais e escritos na escola. Trad. Roxane Rojo e Glaís Sales Cordeiro. Campinas: Mercado de Letras, 2004. p. 95-128.

DOLZ, J. Produire des textes pour mieux comprendre: L'enseignement du discours argumentative. In: REUTER, Y. (org.). Les interactions lecture-écriture. Bern: Peter Lang, 1994.

DOLZ, J.; SCHNEUWLY, B. Gêneros e progressão em expressão oral e escrita: elementos para reflexões sobre uma experiência suíça (Francófona). In: SCHNEUWLY, B.; DOLZ, J. (org.). Gêneros orais e escritos na escola. Trad. Roxane Rojo. Campinas: Mercado das letras, 1996. p. 41-70.

GONÇALVES, A. V; HIGA, M. T. I. Sequências tipológicas em artigo de opinião no contexto de vestibular. SIGNUM: Estudos da Linguagem, Londrina, v. 15, n. 3, p. 195-222, dez. 2012. Doi: https://doi.org/10.5433/2237-4876.2012v15n3p195. Disponível em: https://bit.ly/2WtYxY5. Acesso em: 30 jan. 2017.

FARACO, C. A. Norma culta brasileira: desatando alguns nós. São Paulo: Parábola Editorial, 2008.

GUIMARÃES, C. V. A conexão textual em Luz de $5^{a}$ a $8^{a}$ séries do Ensino Fundamental: uma tentativa de formulação de uma gramática textual. In: ROJO, R.; BATISTA, A. (org.). Livro didático de língua portuguesa, letramento e cultura da escrita. Campinas: Mercado de Letras, 2003.

KAUFMAN, A. M.; RODRIGUEZ, M. H. Escola, leitura e produção de textos. Tradução de Inajara Rodrigues. Porto Alegre: Artmed, 1995.

KOCH, I. G. V. Argumentação e linguagem. 13. ed. São Paulo: Cortez, 2011.

KOCH, I. G. V.; ELIAS, V. M. Escrever e argumentar. São Paulo: Contexto, 2016.

LAVILLE, C.; DIONNE, J. A construção do saber: manual de metodologia da pesquisa em ciências humanas. Belo Horizonte: Editora UFMG, 1999.

LIBERALI, F. C. Argumentação em contexto escolar. Campinas: Ed. Pontes, 2013.

LOPES-ROSSI, M. A. G. Gêneros discursivos no ensino de leitura e produção de textos. In: KARWOSKI, A. M.; GAYDECZKA, B.; BRITO, K. S. Gêneros textuais: reflexões e ensino. 4. ed. São Paulo: Parábola Editorial, 2011.

MARCUSCHI, L. A. Produção textual, análise de gêneros e compreensão. São Paulo: Parábola Editorial, 2008.

OLIVEIRA, L. A. Coisas que todo professor de português precisa saber: a teoria na prática. São Paulo: Parábola Editorial, 2010. 
PASSARELLI, L. G. Ensino e correção de textos escolares. São Paulo: Cortez, 2012. PERELMAN, C.; OLBRECHTS-TYTECA, L. Tratado da argumentação - a nova retórica. Tradução de Maria E. G. G. Pereira. São Paulo: Martins Fontes; 1996. RANGEL, E. O. Letramento literário e livro didático de língua portuguesa: “os amores difíceis". In: PAIVA, A.; MARTINS, A.; PAULINO, Z. V. (org.). Literatura e letramento: espaços, suportes e interfaces - o jogo do livro. Belo Horizonte: UFMG, 2003.

RANGEL, E. O.; GAGLIARDI, E.; AMARAL, H. Pontos de vista: caderno do professor: orientação para produção de textos. São Paulo: Cenpec, 2014.

SANTOS, C. F. O ensino da língua escrita na escola: dos tipos aos gêneros. In: SANTOS, C. F.; MENDONÇA, M.; CAVALCANTE, M. C. B. (org.) Diversidade textual: os gêneros na sala de aula. Belo Horizonte: Autêntica, 2007.

SCHNEUWLY, B; DOLZ, J. Gêneros orais e escritos na escola. Tradução de Roxane Rojo e Glaís Sales Cordeiro. Campinas: Mercado de Letras, 2004.

TOULMIN, S. Os usos do argumento. São Paulo: Martins Fontes, 2001.

Data de submissão: 29/01/2018. Data de aprovação: 15/04/2019. 